\title{
On Efficient Use of Modifying Additives in Restoration of Agricultural Machinery
}

\author{
Saychuk O.V., Kolpachenko N.M., Martynenko O.D., Honcharenko O.O.
}

\begin{abstract}
Statistical analysis of gray iron parts quality of agricultural machinery, according to which the Hc measurements were made, has revealed that the level of this characteristic on the surface has different indicators. They vary from 4,3 to $8,0 \mathrm{~A} / \mathrm{cm}$, and on the inside - they reach 5,0 - 9,4 A/cm, which indicates the formation of defects more often in this area. Zones with impaired metal quality (cracks, pores, local stresses, structural deviations of the liquidation phenomena with the formation of non-metallic inclusions) were established by metallographic and micro-X-ray spectral studies, where the Hs indexes increased and reached 7,8-11,3 A/cm.

A new approach, assessing a structure formation at the restoration of body parts from gray iron has been developed, based on detection of defects and structure in them by a non-destructive method according to the $\mathrm{Hs}$ indices and an optical-mathematical method.

Recovery of defects by melting, using a detonation charge from the disposal of ammunition has confirmed the effectiveness of such a modifying impurity when dosing it into a liquid solution of gray iron.

Using technology of casting defects welding in the cases of the distribution box at JSC "HTZ" in restoration of 348 pcs makes 746999 UAH per year.
\end{abstract}

Keywords: non-destructive control, coercive force, modifying impurity, gray cast iron, microstructure, detonation charge, body parts, optical-mathematical method.

\section{INTRODUCTION}

The article analyses the quality of mechanical engineering parts. Innovative technologies of their production were developed based on the analysis. These are engine cylinder liner sleeves of high-strength cast iron cast by the centrifugal method on machines of horizontal type and case details of the agricultural machinery with alternating and identical section made by stationary method from gray cast iron and carbon steel.

Factors in the operation of parts affecting changes in the properties of cast iron are considered. Much attention is paid to changes in chemical composition of alloys, methods of modification and the effect of their deviations on quality and properties of metal castings, structure, occurrence of various

Revised Version Manuscript Received on October 15, 2019.

Oleksandr Saychuk, Doctor, Prof., Doctor of Engineering Sciences, Associate Professor, Director of Educational and Scientific Institute of Technical Service, Professor at the Chair of Technological Systems of Repair Production, Ukraine.

Nadiia Kolpachenko, Ph.D, Assoc. Prof., Candidate of Science (Economics), Associate Professor, Department of Technological Systems of Repair Production, Ukraine

Oleksandr Martynenko, Ph.D, Assoc. Prof., Candidate of Technica Sciences, Associate Professor, Department of Technological Systems of Repair Production. excellence in education of Ukraine.

Oleksandr Honcharenko, Ph.D, Assoc. Prof., Candidate of Technical Sciences, Associate Professor, Department of Technological Systems of Repair Production, Ukraine defects, as well as methods of their recovery.

\section{ANALYSIS OF THE RECENT RESEARCHES AND PUBLICATIONS}

Significant contribution to the development of the theoretical, methodical and practical aspects of restoration of agricultural machinery parts was made by: T. Skoblo, O. Sidashenko，O. Saychuk，O. Klochko，E. Belkin and others. Having analysed domestic and foreign sources of scientific information, data on the production of body parts made of high-strength and gray cast iron have been generalized, regulatory and technical documentation on the requirements to quality assessment, crystallization conditions and metal structure formation have been studied.

\section{METHODOLOGY OF RESEARCH AND MATERIALS}

Statistical analysis and planning of the experiments were performed both directly on the castings, and comparatively on the rings selected from them. The analysis has revealed that the main factors of deviations are: chemical composition, metal structure, presence of non-metallic inclusions, clogging of charge materials with different chemical components, as well as preparation of equipment prior to metal pouring and technology of its modification that did not meet the requirements. [1].

This was accompanied by deviations of different mechanical properties, the structure of the metal and influenced on the formation of defects (pores and cracks, shells, etc.).

\section{DISCUSSION AND RESULTS}

Detailed statistical studies of the properties and structure of castings,using non-destructive magnetic control on coercive force have allowed us to develop defective norms of indications and to look for new innovative solutions. On the basis of such an analysis, a method of effective preheating of a multi-thickness metallic form was developed for filling the sleeves of cylinder liners. In this case the same temperature is ensured at its height and the formation of structural heterogeneity is excluded, as well as localization of deformations in the zones of the sleeve [2], cast into a different-thickness metal form.

In the production of body parts (Fig. 1) from gray cast iron it is important to reliably repair the defects through their cleaning and subsequent welding with a steel electrode [3]. 


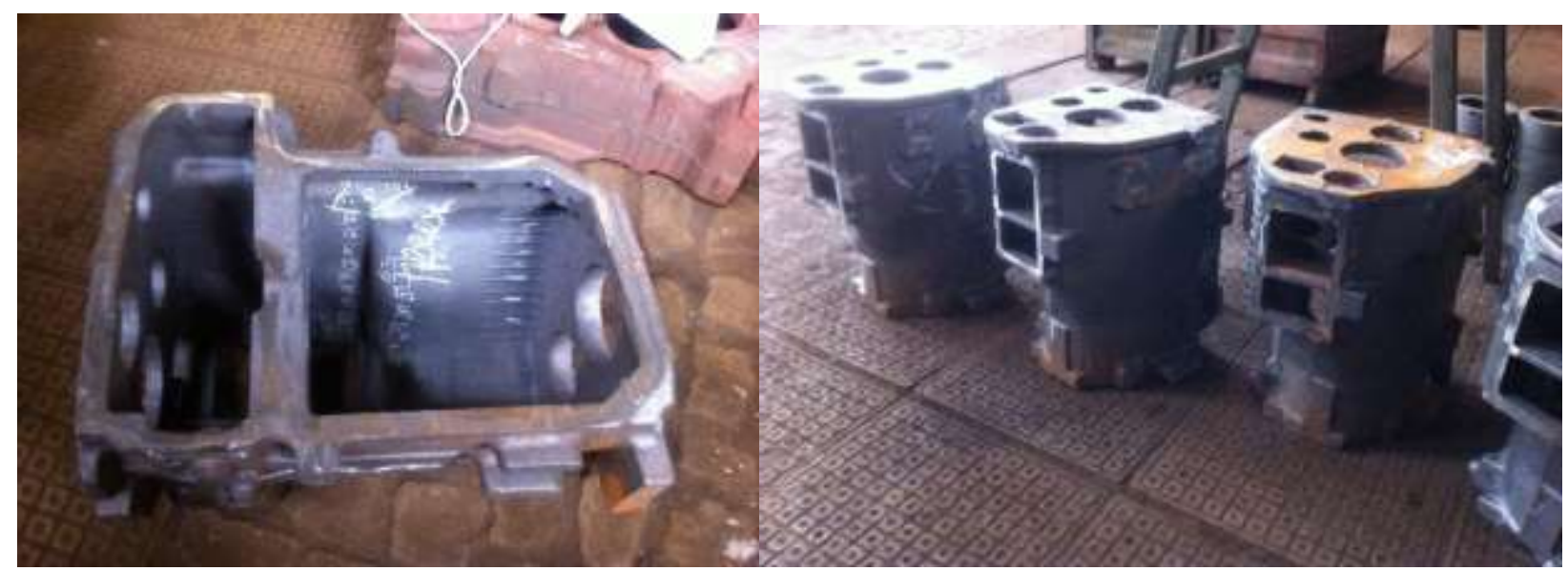

Fig. 1 - Appearance of gray cast iron body parts

Taking into consideration the fact that such material is not technological, and sinks, microcracks are formed additionally in welding defects in the welding zone and at the boundary of the fusion pores, additional modification impurity with detonation charge was used to reduce the temperature of the process and eliminate these defects. It was obtained from disposal of a certain set of ammunition with expired storage term [4]. The resulting charge was separated from the non-magnetic component and crushed. It consisted of nanoand disperse diamonds, a small fraction of graphite, and copper and iron oxides.

To recommend the use of such a modifier, various ways of its introduction were comparatively investigated: in the form of a slip coating with subsequent melting with electrode TsCh-4 ( $\varnothing 3 \mathrm{~mm})$, as well as its coating. On the basis of comparative studies with variant without and with modification the innovative technology providing qualitative repair of defects by welding is offered [5].

Methods of statistical analysis evaluated the effect of chemical composition, non-metallic inclusions, modifying impurities, deviations in the phase composition (appearance of carbides, coarse inclusions of graphite) and their influence on the properties and formation of defects.

Based on complex studies of structure formation, influence of different modification methods by secondary raw materials was studied, which allowed us to obtain new technology of body parts restoration from gray iron by surfacing in the conditions of industrial production.

During the research, the possibility to predict the structure, defects and stress state of castings by non-destructive method of control was analysed. Different approaches were used in conducting the experiments, combining different research and measurement methods, determining defective norms of indications for castings in the conditions of industrial production.

The content of the components in the metal of the castings was evaluated by chemical and spectral analyzes, and their local distribution by micro-ray spectroscopy. Alloys structure was studied with an optical microscope at magnifications 100-1000 times and on an electronic YSM-820 Link "YEOL" with the system of X-ray microanalysis. The distribution of the components was also studied by the method of thermoelectronic emission.

Different zones structure was studied in detail in the restoration of defects. A new approach, evaluating all the formed phases by photographs of different magnifications, obtained by the method of opto-mathematical description, substantiating the advantages of the proposed technology, was applied.

To evaluate the indicators of structure change and occurrence of stresses, defects, we used the experience in influencing the indicators and a measurement method in studies [6], as well as the developed standard [7]. Depending on the size and measurement tasks, the ranges and the type of magnetic converter were selected.

A magnetic analyzer KRM-Ts-K2M (Fig. 2) [6] was used in the work. A single approach of complex research to the assessment of structure and stresses was performed by it, according to the coercive force with the development of defective norms.

To assess the influence of various factors on the measurement results, the location of the converter on the parts during the experiments; the impact of the evaluated surface quality, sensitivity of the method to changes in the structure and type of defects formed; changes in stresses, properties and the environment were considered.

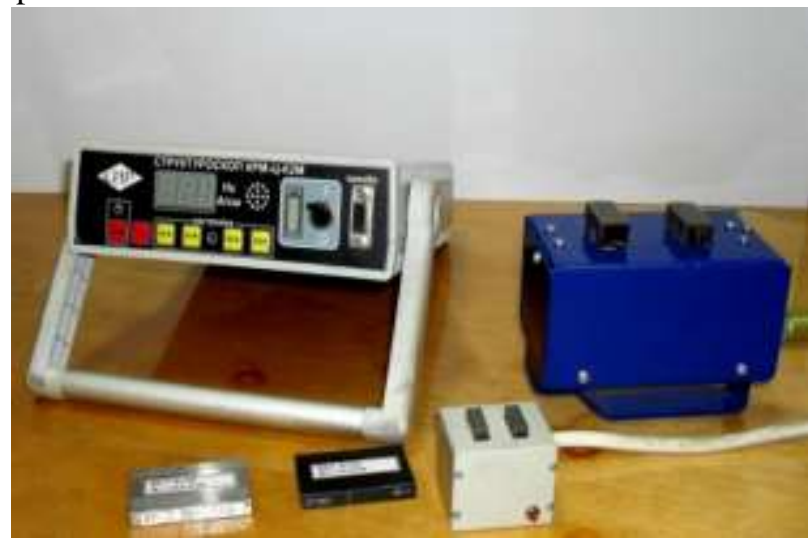

Fig. 2 - General view of the KRM-C-K2M magnetic analyzer with overhead converters of different size

The standard covers parts, rolled metal for agricultural machinery and spare parts for manufactured machinery, as

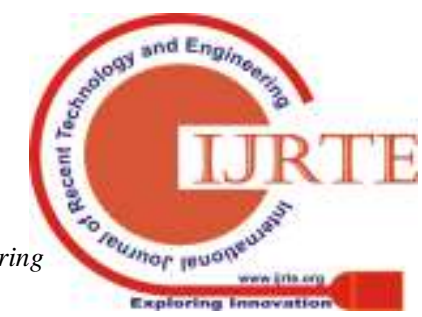


well as products that require quality control during the operation. It establishes general requirements and recommendations for quality control, magnetic characteristic resource evaluation - coercive force $(\mathrm{Hc})$ for parts made of ferromagnetic grades of steels and alloys, including cast iron.

The standard includes references to a number of regulatory documents [8] that have been taken into account in measurement approaches where factors affecting the measurement results are considered: failure to perform instrument calibration; operator errors; insufficient measurement volume to handle experimental metrics high (> $30{ }^{\circ} \mathrm{C}$ ) and low ambient temperature (up to $10^{\circ} \mathrm{C}$ ); deviation from the chosen research methodology; the shape and size of measurement zones; a significant change in chemical composition, machining parameters of the workpiece and its residual magnetization.

Optical-mathematical method of research is one of the complex methods based on the detection of previous metallographic, electron-microscopic, locally spectral evaluations of the chemical and phase composition of cast iron. To change the degree of its manufacturability, various methods and parameters for the introduction of modifying impurity were used. This is practically free secondary raw material from the disposal of ammunition, specially ground and processed for their use.

This research method has been used for the first time not only to identify the qualitative and quantitative composition, different zones of the recovered layer, but also to search for, to ensure the maximum bonds of the same phases between the recovered deposition zone, transition, the base, because it forms the maximum adhesion strength and minimizes stresses. In addition, the way and place of stresses inhomogeneities in the surfacing zones and around the rough inclusions of graphite that are the places of defective zones formation were analyzed. Their influence on changes in the dislocation structure and diffusion processes was considered.

The methodological approach was based on studies of microstructure photographs obtained on an optical microscope "MIM-8M", an electronic "YEOL JSM-6390LV", scanning "YSM-820" Link "YEOL" with magnifications from 70 to 1000 times.

Cells $C(x, y)$ with different pixels $(2 \times 2,3 \times 3,10 \times 10$, etc. $)$ were studied to establish maximum relationship of colors (identical in chemical phase composition) between different zones. Cell $3 \times 3$ pixels for calculations is shown in Fig. 3 . Similarly, other cells with more pixels were formed. The phase calculations, according to their relation in different zones and obtaining histograms, were additionally performed analyzing cells of $10 \times 10$ pixels.

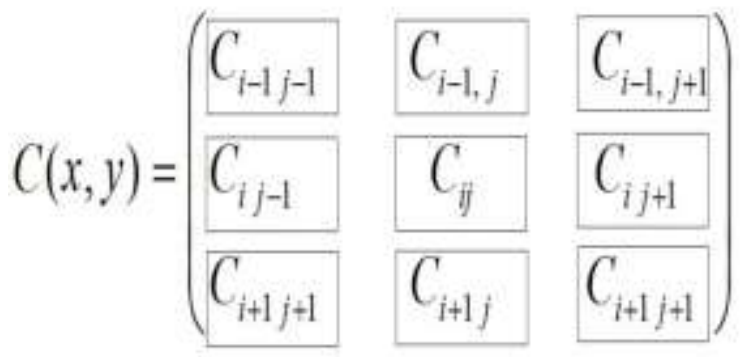

Fig. 3 - Arrangement of pixels around the average, with row number $i$ and column $\mathbf{j}$. Color $\mathrm{C}_{-} \mathrm{ij}$ is average in bmp 256 shades
The technique of optical-mathematical research is based on the provisions of hydrodynamics, where each pixel coordinate of the digital image is given a value of a conditional color. This corresponds to the absolute value of the Laplacian, which describes the heterogeneity of chemical elements distribution or the absolute divergence, characterizing density of the fragment. For this purpose, indicators are used to describe local differential relations between the conditional colors estimated according to the finite difference indices. Such indicators are calculated on the basis of the Navier-Stokes differential equations, presented in the work in the form of changing functions of flow and vortex in finite-difference form [9-11]. They are also used to obtain histograms of the integral distribution of the corresponding structures in each image fragment, corresponding to qualitative indicators (characteristics) of the structure evaluation.

Photos of gray cast iron microstructures taken in bmp format of $1300 \times 1000$ pixel were processed, using a computer. This format has 256 colors from 0 to 255 inclusive. This number is related to the representation of colors in computer memory by the RGB color model. To represent all possible colors and shades, combinations of three primary colors are used: red (R), green $(\mathrm{G})$ and blue (B). Each component in the RGB model is encoded with a number that indicates saturation of that component. Moreover, the number of gradations (shades) of each component depends on how much memory is allocated to store its binary code in the memory of the computer. Traditionally, a 24-bit RGB model was used, with 8 bits allocated to each component. Accordingly, each of the base colors has $28=256$ shades. Gray is a mix of all three base colors in equal proportions, so it also has 256 shades.

Photos of microstructures in $\mathrm{bmp}$ format are digitized in pgm format (grayscale image format) to be calculated by the program, which is necessary due to the peculiarities of the computing equipment.

The program calculates a single photo for about 40 minutes and outputs a file for each fragment of its coordinates, the number of combinations, the numbers of colors that are combined, the average number of pixels that are combined, and the percentage of combinations within the fragment $10 \times 10$. The file sizes of the results obtained are about 3,5 megabytes.

In the first stage, 256 colors are divided into 17 intervals, and then in the absence of some, they are combined. According to the research, colors 1-2 are attributed to graphite; 3-10 to ferrite phases; 11-17 to carbide.

Optical-mathematical analysis examined the photographs of micro- and electronic images of structures in order to evaluate the homogeneity of the phase distribution and to identify those that would provide the greatest connection between local recovery zones and the primary (original) cast iron.

The change in the dislocation structure, which was previously detected by vacuum etching, around the zones of coarse graphite inclusions subjected to stress after casting of 
gray cast iron parts, was first studied under conditions of local defects and oxidation. The cast from the action contributes to the increase of free energy due to the growth of plastic deformation and its further decrease in the development of defects (dislocations), their ordering (formation of walls, cells). As a criterion describing the changes in the dislocation structure, its density was the energy parameter - the energy dissipation strength [11]:

$$
M=D(x, y) \cdot L(\mathrm{x}, \mathrm{y}) \text {, }
$$

presented as linking divergence and Laplace functions $C(x, y)$, where $x, y$ - coordinates of metallographic image points.

This divergence $D(x, y)$ describes density of the image fragment (compaction and discharge zones) and the Laplacian $L(x, y)$ diffusion of chemical components.

$$
D(x, y)=\operatorname{div} C(x, y)=\frac{\partial C(x, y)}{\partial x}+\frac{\partial C(x, y)}{\partial y}
$$
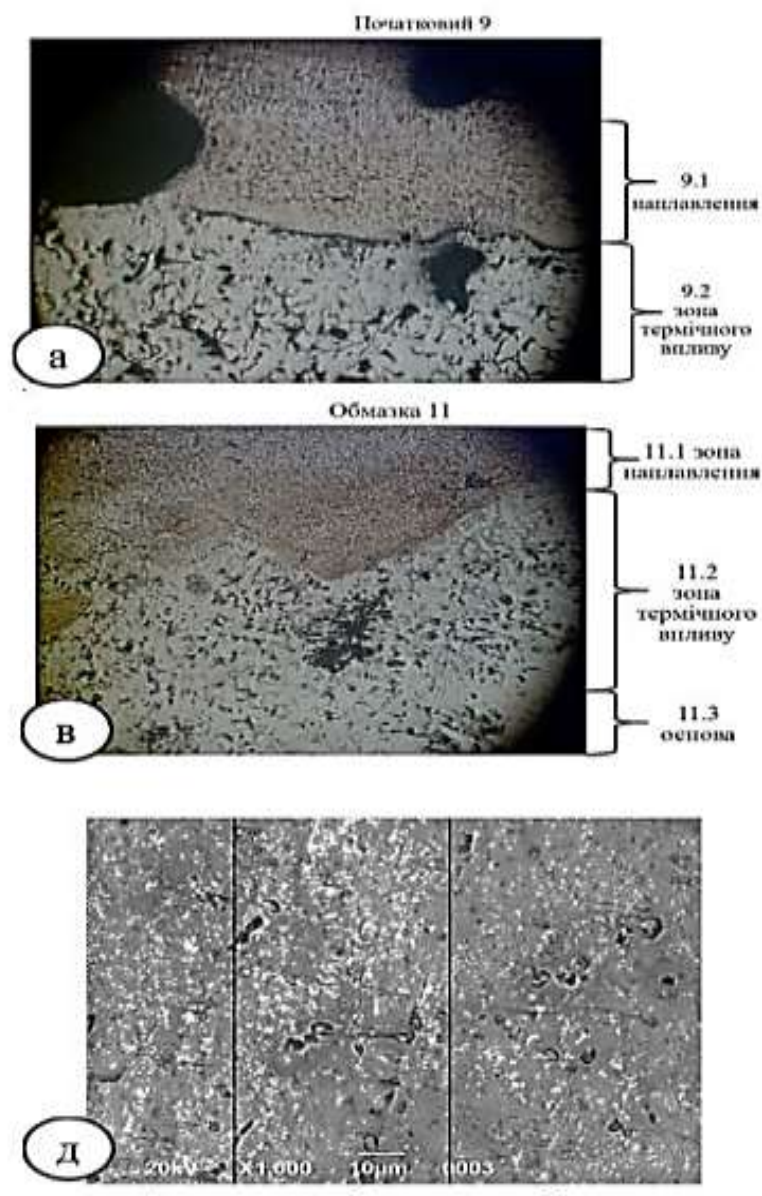

1

2

$$
L(x, y)=\Delta C(x, y)=\frac{\partial^{2} C(x, y)}{\partial x^{2}}+\frac{\partial^{2} C(x, y)}{\partial y^{2}}
$$

In this case, $C(x, y)$ in finite-difference form has a matrix $3 \times 3$ pixels, according to Fig. 3 . Processing of such a matrix was performed by sequential scanning of each pixel and $C_{i j}$ is considered average. This pixel of the central image was used as the coordinate. Since the energy state of the metal is not equilibrium during deformation, according to the calculations, this parameter corresponds to values that will differ in signs.

Photographs for microscopic and - electron microscopic analyzes have been selected for structural formation studies (Fig. 4), each of which represents three zones of forming structures in the restoration of an artificial crack: the base, the transition zone and the surfacing.

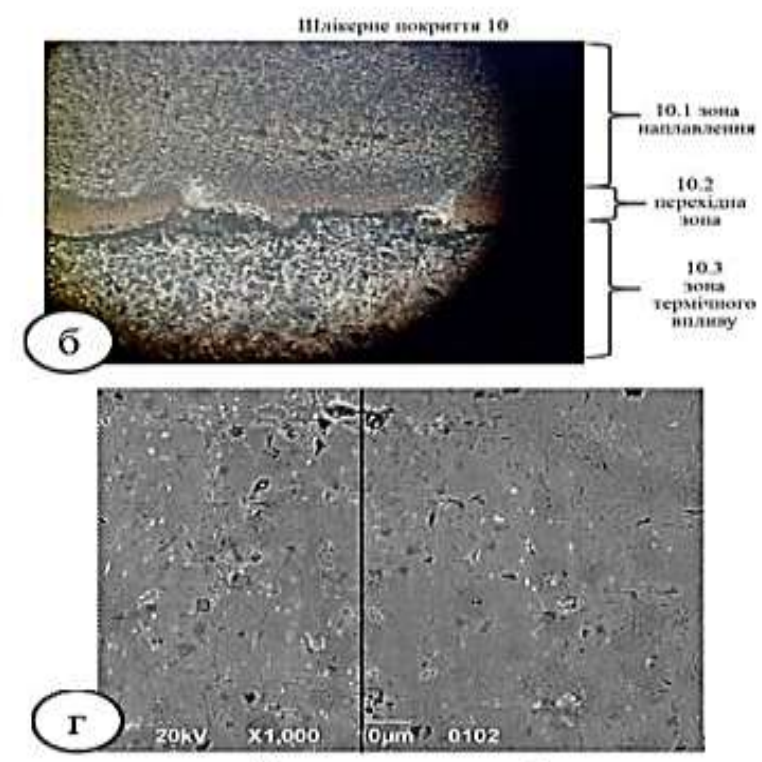

5

4

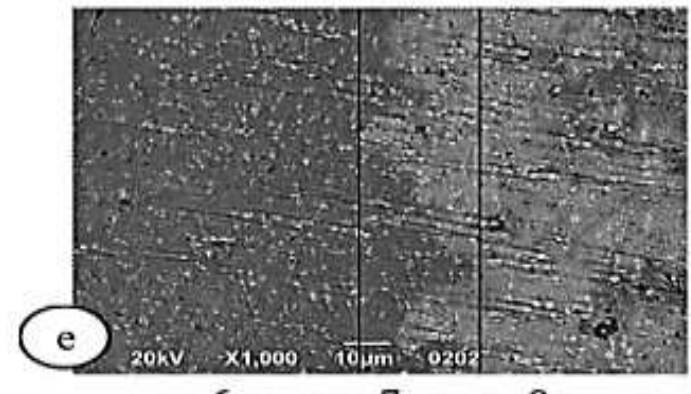

6

7

8

Fig. 4 - Investigated photographs using the developed method of optical-mathematical analysis: a, g - structure without modifying impurity; $b$, $d$ - slip coating; $c$, e - coating of the electrode with the dosed introduction of the modifier

Analysis of the first crack recovery option (without the use

In this case, the comparison of the structure was performed by modifying the slip coating, dosed introduction of impurities and without using additional application of impurities. As a modifier a non-magnetic component of the detonation charge obtained from the disposal of ammunition was used.

The studies were performed on discarded gearboxes used for agricultural machinery. The same parameters of artificially formed cracks were used. The defects were welded with electrode TsCh-4 $\varnothing 3.0 \mathrm{~mm}$ with the imposition of short rollers $40-60 \mathrm{~mm}$ long. of a modifying admixture) includes combinations of ferrite phases, which are more basic than the deposited layer. There is also more carbide phase in number and combinations in the parent metal. The difference is $11-13 \%$. However, the individual combinations do not exceed $5-7 \%$. 
The second option in the restoration of cracks involves modification of the liquid bath using the application of a slip coating, followed by its melting. In this case, the modification process increases the number of phase combinations. The proportion of ferrite phases corresponds to the percentage of common areas of the photograph, where it significantly increases from $71.2 \%$ to $85.6 \%$ compared to the first variant, in which there was no modification. The ratio by number of combinations corresponds to 9 pairs for ferrite components. It is possible to assume that the colors of the base and the surfacing zone acquire close values and that the boundary of the distribution is not clearly shown and corresponds to the criterion of turbulence. This characterizes artificial acceleration of the transition from laminar flow to turbulent by introducing of special impurities - turbulators into the flow.

The third photograph, which reflects the result of the
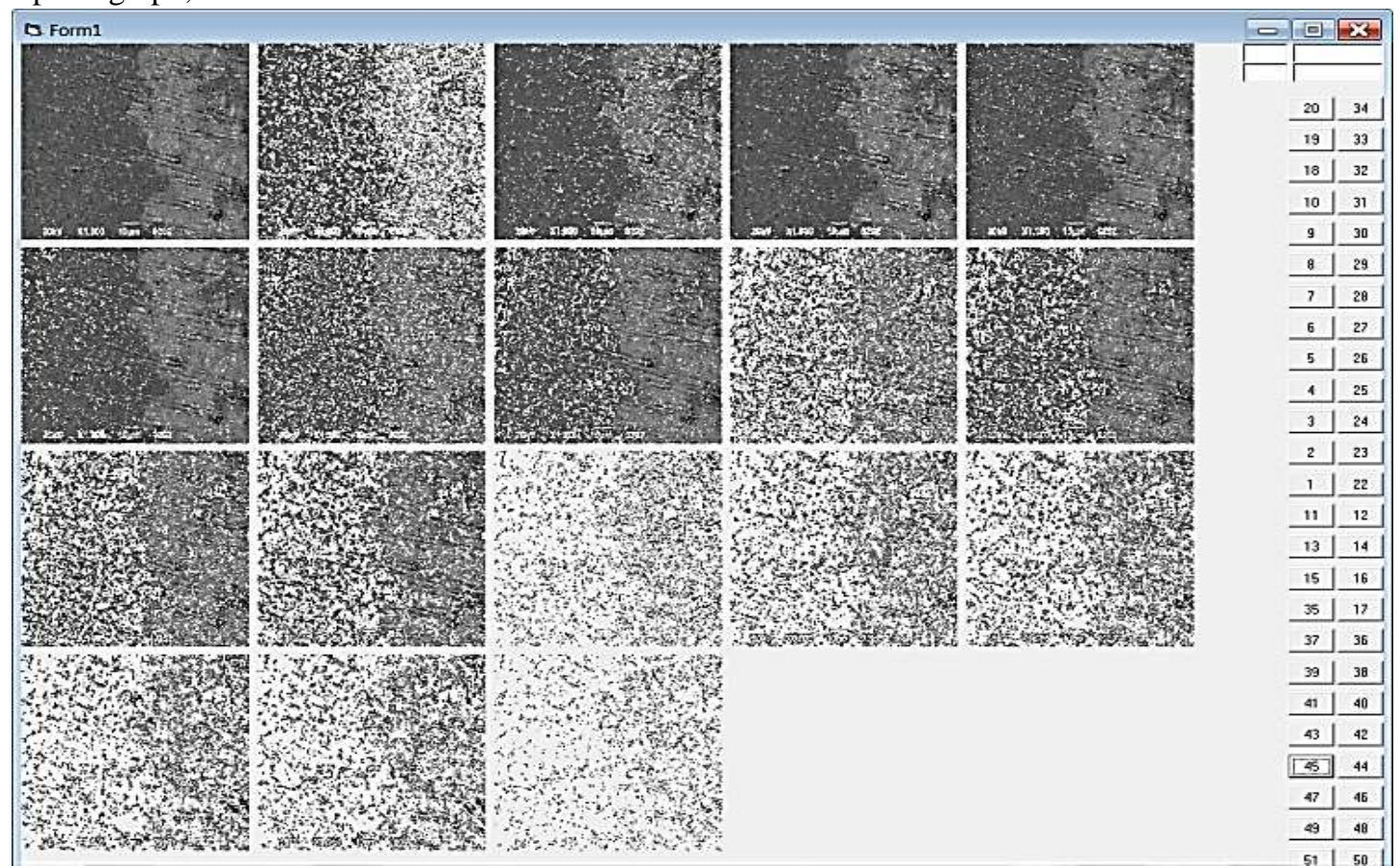

Fig. 5 - Optical-mathematical description of the formed structure when applying a modifying impurity in the form of the introduction of electrode coating

in the surfacing zone with the formation of a large number of small pores. The surfacing zone is characterized by an increase in grain.

The identified structural changes that have provided the highest efficiency, have been achieved by reducing the heat input as well as development of turbulence with the introduction of nonsoluble and dispersed diamonds that play the role of local microcoolers. 




Fig. 7 - Optical-mathematical description of the formed structure without admixture of modifier

The economic effect of using the technology of welding casting defects in the cases of the distribution box at JSC "HTZ" in the restoration of 348 pcs is $746999 \mathrm{UAH}$ for a year.

\section{CONCLUSION}

On the basis of the performed researches the following results have been obtained. Statistical analysis of the quality of gray iron parts of agricultural machinery, according to which the Hc measurements were made, has revealed that the level of this characteristic on the surface has different indicators, varying from 4,3 to $8,0 \mathrm{~A} / \mathrm{cm}$, and on the inside they reach $5,0-9,4 \mathrm{~A} / \mathrm{cm}$, indicating the formation of defects more often in this area. By metallographic and micro-X-ray spectral studies, zones with disturbances of the metal quality (cracks, pores, local stresses, structural deviations of the liquidation phenomena with the formation of non-metallic inclusions) were established, where the Hs indexes increased and reached 7.8-11.3 $\mathrm{A} / \mathrm{cm}$.

A new approach to assessment of structure formation at the restoration of body parts from gray iron has been developed based on detection of defects and structure in them by non-destructive method according to the Hs indices and opto-mathematical method.

Recovery of defects by melting, using a detonation charge from the disposal of ammunition, has confirmed the effectiveness of such a modifying impurity use when dosing it into a liquid solution of gray iron.

\section{REFERENCES}

1. Method for assessing product quality by non-destructive method: US Pat. 95287 Ukraine, IPC G01N 27/82 (2006.01). No. a201406020; claimed 02.06.2014; publ. 12/25/2014, Bul. №24

2. T. Skoblo, A. Sidashenko, A. Saychuk et al. Assessment of the quality of gray iron castings by non-destructive testing methods. International scientific and technical journal "Foundry". 2014. No. 12. pp. 2-4.
3. Saychuk A. The technology for the production of body parts from cast iron with spherical and vermicular graphite. Information and analytical international technical journal "Industry in Focus" January. 2017. No1 |50|. pp. 54-58

4. Markov A. Improving the operational stability of parts of agricultural engineering using recycled materials. The scientific and practical journal "Agrotechnics and energy supply" Orel, 2015. No. 5 (9). pp. 12-25.

5. T. Skoblo, A. Sidashenko, A. Saychuk et al. The effect of modification with carbon-containing powder additives on the wear resistance during coating / Information and analytical international technical journal "Industry in Focus" October 2016. No.10 |47|. pp. 54-58.

6. Method of assessing the quality of gray iron products by non-destructive method: US Pat. 100780 Ukraine, IPC: G01N 27/82, G01N 27/00 No. u201501491; claimed 02/20/15; publ. 08/10/2015, Bul. №15.

7. Ministry of agricultural policy of ukraine standard "Non-destructive quality control by magnetic method of agricultural machine parts during maintenance and repair" SOU 29.32.4-37-532: 2007, Kyiv, 2007.

8. ISO 9000 (series of standars). Systems of quality management.

9. T. Skoblo, O. Klochko, A. Sidashenko, R. Sokolov Heat Treatment of TwoLayer AlloyedIron Rollers / ISSN 09670912, Steel in Translation, 2013, Vol. 43, No. 9, pp. 603-606.

10. T. Skoblo, E. Belkin, O. Klochko. Application substantiation of Navier-Stokes hydrodynamics equations for the analysis of metallographic images. Materiały VII Międzynarodowej naukowi-praktycznej konferencji «Europejska nauka XXI powieką - 2011» Volume 21. Techniczne nauki: Przemyśl. Nauka i studia. pp. 94-96.

11. T. Skoblo, O. Klochko, E. Belkin The Use of Computer Analysis of Metallographic Images in thx Study of the Structure of High-Chromium Cast Iron. Inorganic Matbrials English translation of selected articles from Zavodskaya Laboratoriya. Diagnostika Materialov. 2012 T. 78, № 6. pp. 35-42.
Blue Eyes Intelligence Engineering \& Sciences Publication 


\section{AUTHOR PROFILE}

Oleksandr Saychuk, Doctor, Prof.

Doctor of Engineering Sciences, Associate Professor, Director of Educational and Scientific Institute of Technical Service, Professor at the Chair of Technological Systems of Repair Production.

In 2000 graduated from the Kharkiv State Technical University of Agriculture and received a full degree in the specialty "Mechanization of Agriculture" and obtained a Master's degree in mechanization in agriculture.

Since September 2000 - Senior Laboratory of the Machine Repair Department. Since September 2004 - head of the laboratory of the department of repair of cars. Since September 2005 - assistant of the department of repair of tractors, cars and agricultural machinery.

Since September 2013 - Associate Professor of the Department of Technological Systems of Repair Production.

Since September, 2017 - the director of educational-scientific institute of technical service.

In 2019 defended a thesis on specialty "Science of Materials" and received a degree of Doctor of Engineering Sciences. Direction of scientific research: Theoretical and technological bases of control of the structure and properties of pig iron of various functional purposes.

More than 21 publications in professional editions of Ukraine. Participation in international conferences, internship at Academia WSB, Poland.

Fields of interest: «Technological systems of repair production», «Introduction to the specialty» «Innovations in the industry».

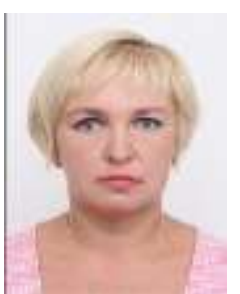

Nadiia Kolpachenko, Ph.D, Assoc. Prof.

Candidate of Science (Economics), Associate Professor, Department of Technological Systems of Repair Production.

In 2004 graduated from the State Technical University of Agriculture and received a ful degree in Management of Organizations and received a qualification as an Economist.

Since September 2004 - assistant of the Department of Production, Business and Management of the Faculty of Management.

Since September 2009 - Senior Lecturer of the Department of Production, Business and Management of the Academic Institute of Business and Management.

Since September 2018 - Associate Professor of the Department of Technological systems of Repair Production of the Scientific-Technical Institute of Technical Service.

In 2017 defended dissertation in the specialty "Economics and Management of Enterprises (by Types of Economic Activity)" and received a Ph.D in Economics. Direction of scientific research: Organizational and economic principles of agricultural enterprises bio-energy potential development.

More than 15 publications in professional editions of Ukraine.

Participation in international conferences, internship at Academia WSB, Poland.

Fields of interest: "Economics and Management of Enterprises", "Economics of machine-building enterprise", "System of technologies of agrotechnical services enterprises", "Innovative development of enterprises".

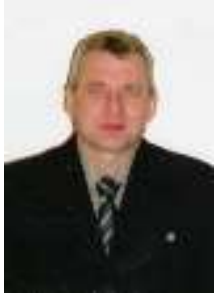

Oleksandr Martynenko, Ph.D, Assoc. Prof

Candidate of Technical Sciences, Associate Professor, Department of Technological Systems of Repair Production. excellence in education of Ukraine

In 1983, he graduated from the Slavic Agricultural College. From 1983 to 1985 . served in the ranks of the Soviet Army. In 1985 enrolling in the Melitopol Institute of Mechanization and Electrification of Agriculture, and in 1990. Graduated from Kharkiv Institute of Mechanization and Electrification of Agriculture.

After graduating from the Institute he worked as a research fellow. From 1991 to 1994 studied in a day graduate school. Since 1994 began to work as an assistant of the department of repair of cars, and since 2000. - Senior Lecturer

After defense of the candidate's dissertation in 2003 Martynenko O.D. Assigned a Candidate Degree in Engineering. In 2004 he was elected assistant professor, and in 2005 Associated professor of the department of repair of tractors, cars and agricultural machines.

For many years of fruitful work Martynenko O.D. was awarded the "Diploma of honor" of the Ministry of Education and Science of Ukraine and the honors of the Ministry of Education and Science of Ukraine - the breastplate "Excellence in education"

Areas of scientific work are the repair of machines and equipment, laser and electrospark technology for restoration and hardening of machine parts.

$\mathrm{He}$ is the author of more than 120 scientific works including the monographs - 2, educational manuals, textbooks - 7, author's certificates over 10, methodological and educational developments more than 35 .

Fields of interest: "Installation, diagnostics and repair of equipment for processing and food industries", "Repair of machines", "Repair of machines and equipment", "Design of production processes and technical service enterprises", "Expert examination of technical condition of equipment".

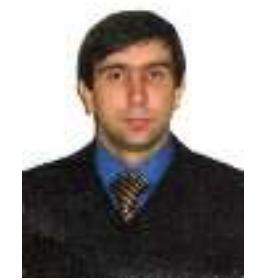

Oleksandr Honcharenko, Ph.D, Assoc. Prof. Candidate of Technical Sciences, Associate Professor, Department of Technological Systems of Repair Production.

In 2001 he graduated from State Technical University of Agriculture obtained a degree in mechanical engineer.

From 2004 to 2006 he internship in Denmark.

From 2007 to 2009, he served as the Chairman of the Council of Young Scientists of the KhNTUA.

In 2010 he got her $\mathrm{PhD}$ thesis on the theme: «Development of technology and ground of parameters of renewal of spline billows of agricultural machines», specialty «Machinery and ways of agricultural production mechanization».

From December, 2011 till now - an Associate Professor of the department of technological systems of repair production.

He is the author of more than 55 scientific works, including: textbooks, articles, methodical and educational developments.

Fields of interest: Development of technologies for the restoration of a wide range of engineering parts, the introduction of modern methods for assessing reliability 